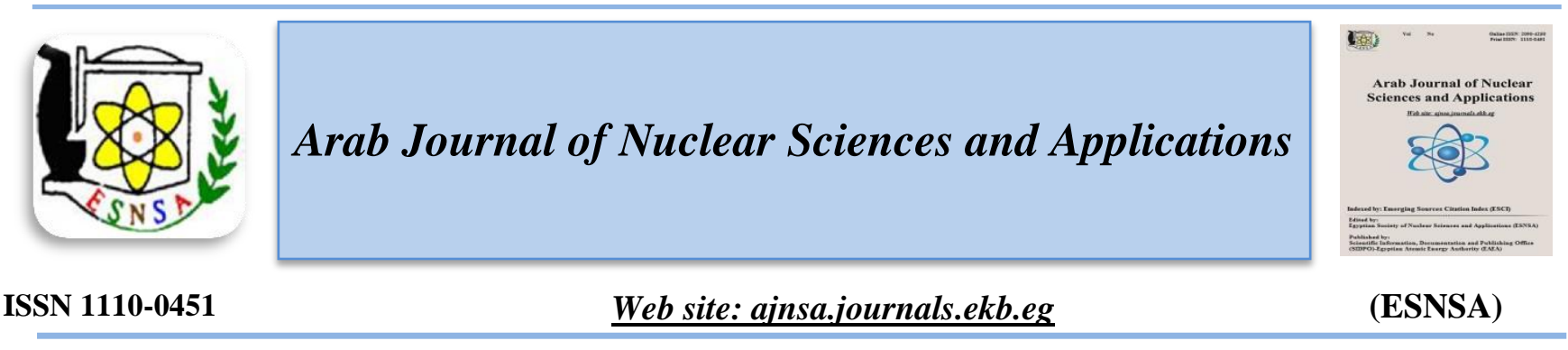

\title{
Ameliorative Effect of Vitamin E against Radiofrequency Radiation Emitted from Mobile Phone-Induced Hematological and Histopathological Alterations in Male Albino Mice
}

\author{
Mona H. Ibraheim ${ }^{1}$, Aziza Amin ${ }^{2}$ \\ ${ }^{1}$ Department of Physics, Faculty of Science, Zagazig University, Egypt \\ ${ }^{2}$ Department of Pathology, Faculty of Veterinary Medicine, Benha University, Egypt
}

Received 16 March 2020

Accepted 24 Aug. 2020
Radiofrequency radiation is widespread in the surrounding environment and their frequent sources are mobile phones. Consequently, the present research aims at studying the effect of radiofrequency radiation released from mobile phones on some hematological parameters (RBC, HB, MCV, MCH, MCHC, WBC, P LT, LYM \%) and histopathological changes in male white mice. In this work, forty adult male albino mice (25-30 gm weight) were divided into four equal groups; A, B, C, and D. Group A was used as a negative control group, Group B was used as a negative control group for vitamin $\mathrm{E}$ solution, group C was exposed to EMR for $2 \mathrm{hr}$ /day for 3 weeks without vitamin $E$ and Group D, was treated with Vitamin E solution and exposed to EMR for $2 \mathrm{hr} /$ day for 3 weeks. The obtained results revealed that significant changes in RBCs, Hb, HCT, MCV, MCHC, PLT, and WBCs were observed in group C. Additionally, variable histopathological alterations in the liver, kidney, lung, heart, spleen, and brain post-exposure to mobile phone radiation were also demonstrated. Vitamin $E$ has improved these harmful effects induced by radiofrequency radiation on different investigated tissues via their capacity to decline the pathological alterations demonstrated in these organs post-exposure to mobile phone radiation as well as via improving different evaluated blood parameters. Consequently, it could be concluded that vitamin $E$ was able extensively to reduce the harmful influences of mobile phone radiation on blood parameters and the histopathological changes in the liver, kidney, lung, heart, spleen and brain tissues.

Keywords: Mobile phone radiation, vitamin E, Hematological parameters, Histopathology

\section{Introduction}

In the last few years, mobile devices have been widely used that led to great concern about potential dangers. More than $50 \%$ of the people in many countries use mobile telephones that are the only telephones accessible in some places around the world. For data transmission, such devices are using radiofrequency waves and the frequency band used for this varies between countries [1].Cellular phones generate heat and release radiofrequency radiations as non-ionizing electromagnetic radiations of 800-2 $200 \mathrm{MHz}$ [2]. These Electromagnetic radiations have thermal and non-thermal influences on different systems. Mobile phone radiation affects metabolic progression in the exposed body and causes numerous changes in cells via different mechanisms [3]. The prospective health impacts of heat and radiofrequency radiation from cell phones are very serious. There is accruing evidence reported that exposure to the radio-frequency (RF) radiation released from cell phones and or their

Corresponding author: mhmekky@zu.edu.eg.

DOI: 10.21608/ajnsa.2020.25996.1339

CScientific Information, Documentation and Publishing Office (SIDPO)-EAEA 
improper stations could affect people's health [4].EMR exposure from mobile telephones was documented to vary in their effects depending on numerous factors, such as exposure period, distance from various sources, species and tissues plus exposure conditions [5].

Radiofrequency radiations emitted from cell phones cause a significant decline in hematological parameters [6, 7, 8]. In contrast, a marked elevation in the leukocytic counts was detected post-exposure to radiofrequency radiations from mobile phones [8].

Vitamin E, a group of fat-soluble compounds, is first discovered by Evans and Bishop in 1922 to have specific antioxidant activity vital to health. Vitamins can be stored within the fatty tissues of animals and humans because of its fat-soluble property; consequently, they do not have to be consumed daily [9]. Antioxidants as vitamins E and $\mathrm{C}$, coenzyme $\mathrm{Q}$, glutathione and selenium can work together, thus preventing the lipid peroxidation and cellular destruction [10].

Vitamin E functions are a powerful chain-breaking antioxidant that prevents the development of molecules of reactive oxygen species when fats are oxidized and during the spread of free radical reactions. Consequently, the current study was designed to investigate the effects of vitamin $\mathrm{E}$ against the harmful hematological and histopathological alterations induced by radiofrequency radiation released from mobile phones on male albino mice.

\section{Material and Methods}

\section{Experimental Animals}

Forty adult male albino mice weighing about 25$30 \mathrm{gm}$ were obtained from the breeding farm, Faculty of Veterinary Medicine, Zagazig University. Mice were divided randomly into four plastic cages for one week before the experiment starts for adaptation. Mice were maintained under constant environmental conditions at $25^{\circ} \mathrm{C} \pm 3$. Animals were divided randomly into four groups ten per each. Group A, a negative control group (unexposed), was kept under fixed situations of housing and handling until the end of the experiment, while Group B, unexposed negative control group, was given $200 \mathrm{mg} / \mathrm{kg}$ B.wt Vitamin $\mathrm{E}$ as solute preparation (Sigma Industrial Co. ltd. Egypt) as an antioxidant material (along with drinking water). Group $\mathrm{C}$ was exposed to the Mobile phone EMR for $2 \mathrm{hr} /$ day, Group D after adding $200 \mathrm{mg} / \mathrm{kg}$ B.wt vitamin $\mathrm{E}$ was exposed to the mobile phone EMR for $2 \mathrm{hr} /$ day. The whole body of mice was exposed to radiofrequency radiations emitted from a cell phone (Nokia 3310, power $0.96 \mathrm{~W} / \mathrm{Kg}$, intensity $\left.1.3 \times 10^{4} \mathrm{~W} / \mathrm{m}^{2}\right), 2 \mathrm{hr}$ daily for three weeks by putting Mobile phone on top of each cage during the hours of exposure. Through the study, all animals including the control group were fed on a laboratory diet and water ad libitum. The current work was conducted following the ethical approval of Zagazig University's Ethical Commission for Animal Experiments.

\section{Exposure Equipment}

A commercially available global system for mobile communication (GSM) cellular mobiles (Nokia 3310, Finland) was used in this study. This is the main network for operating mobile phones working in Egypt, peak power 1 watt, with a modulation type of Gaussian Minimum Shift Keying (GMSK), pulse duration $4.6 \mathrm{~ms}$, a pulse frequency $217 \mathrm{~Hz}$ and the average power output $460 \mathrm{mw}$, intensity $1.3 \times 10^{-4} \mathrm{~W} / \mathrm{m}^{2}$ with whole body average specific absorption rate (SAR) of 0.4 $\mathrm{W} / \mathrm{Kg}$, for 2 cycles of $60 \mathrm{~min}$ exposure with a 15 min interval each day.

\section{Laboratory analysis \\ Hematological studies}

At the end of the study, all animals from all groups were sacrificed. Collection of blood samples were done either on $0.2 \%$ EDTA anti-coagulant for evaluation of arthrogram: Red blood cell (RBC), Hemoglobin (HB), Mean corpuscular volume (MCV), Mean corpuscular hemoglobin $(\mathrm{MCH})$, Mean corpuscular hemoglobin concentration (MCHC) and leukogram (total and differential leukocytic count, LCT) and on ammonium oxalate anticoagulant for platelets count (PLT) using Leishman stain following standard techniques according to a previous study [11].

\section{Histopathological examination}

Specimens from various organs (liver, kidney, lung, heart, spleen, and brain) of the sacrificed animals from all groups were collected, and then fixed in $10 \%$ neutral buffered formalin. Following proper dehydration and clearing, the samples were embedded in paraffin wax. Sections about $5 \mu \mathrm{m}$ thickness were prepared and stained with hematoxylin and eosin stain (H\&E) for histopathological examinations according to earlier publication [12]. 
According to the severity and distribution of pathological alterations, the detected pathological lesions were graded qualitatively as follows: (-), normal histological texture, $(+)$ means mild degree of pathological alterations $(+=<25 \%$ of the described tissue was affected); (++) means moderate degree of pathological changes $(++=$ $25 \%$ up to $50 \%$ of the described tissue was affected); (+++) means severe degree of pathological alterations $(+++=<50 \%$ of the described tissue was affected). Additionally, the percentage of incidence of different pathological lesions was also reported.

\section{Statistical analysis}

Data were analyzed using a commercially available statistical software package (SPSS v. 22.0). Results were presented as means \pm SD. Statistical significance was determined by the level of $\mathrm{p}<0.05$ using the Student's t-test.

\section{Results}

\section{Hematological studies}

The mean values of blood parameters :(RBCs, HB, HCT, MCV, MCH, MCHC, PLT, LCT) were summarized in Table (1) for all the investigated groups at $(\mathrm{p}<0.05)$. It is clear that there was a significant decrease in all blood parameters of rats obtained from group $\mathrm{C}$ in comparison to the negative control groups (group $\mathrm{A}$ and $\mathrm{B}$ ). Interestingly, there was a marked improvement in all blood parameters of rats obtained from vitamin E protected group (group D). It was observed from the obtained results listed in the Table (1), the animals of group $\mathrm{C}$ suffered from anemia as the number of RBCs in group $\mathrm{C}$ was extensively reduced $(8.18 \pm 0.02)$ in comparison to the negative control groups (group A 11.26 \pm 0.29 ), and group B $(11.56 \pm 0.19)$ as well as the exposed and protected group (group $\mathrm{D}, 9.37 \pm 0.01$ ).

\section{Histopathological examination:}

The microscopical examination of hematoxylin and eosin (H \& E) stained sections of liver, kidney, lung, heart, spleen, and brain were evaluated as well as the severity and percentage of occurrence of all histopathological lesions in every group were summarized in Table (2).

Normal histological structure of different investigated organs (liver, kidney, lung, heart, spleen and brain) obtained from mice of groups $\mathrm{A}$ and $\mathrm{B}$ was detected during their microscopical examination (data not shown). Meanwhile, there were marked histopathological alterations demonstrated in different investigated organs obtained from animals exposed to radiofrequency radiation (group C) as the liver showed dilatation and congestion of the hepatic blood vessels with perivascular mononuclear leukocytic cellular infiltrations mainly lymphocytes and few macrophages (Fig. 1a) in association with degenerative changes in the wall of blood vessels with hydropic degeneration of the hepatocytes characterized by swollen, pale, vacuolated cytoplasm with pyknotic or absent nuclei (Fig. 1b). Multiple small focal areas of coagulative necrosis that characterized by retention of hepatic cell outline with hyper-eosinophilic cytoplasm of hepatocytes and karyorrhectic nuclear changes were detected in the hepatic parenchyma (Fig. 1c). Meanwhile, in group D mild congestion of the central veins with activation of Keupfer's cells and few perivascular inflammatory cell infiltrations were observed. Accidently, in two treated cases, the hepatocytes showed a mild hydropic degeneration characterized by indistinct vacuolation of the cytoplasm (Fig. 1d). Interestingly, the hepatic tissue of some treated animals showed a normal histological structure with almost intact hepatic cords.

Meanwhile, the microscopical examination of the kidneys obtained from group $\mathrm{C}$ revealed a marked congestion of the renal blood vessels and intertubular capillaries marked hypertrophy of the endothelial cell lining of renal blood vessels with perivascular hemorrhage (Fig. 2a) as well as perivascular mononuclear leukocytic cellular infiltration (Fig. 2b).glomerular hemorrhage, Peritubular, intertubular hemorrhage in association with peri-glomerular and inter-tubular inflammatory cells infiltration and interstitial focal aggregations of mononuclear leukocytes were also seen in the renal cortex (Fig. 2c\&d). Multifocally, the lining epithelium of large numbers of renal convoluted tubules showed marked vacuolar and hydropic degeneration characterized by swollen pale vacuolated cytoplasm and indistinct cell borders. Occasionally, entire necrosis of the tubular epithelium with shrunken, pyknotic nuclei and loss of cellular details with leukocytic cellular infiltration in the lumen of some affected renal tubules were observed (Fig. 2e). Multifocally, vacuolation of the endothelial cell lining of the glomerular tuft and some glomeruli showed shrinkage of glomerular tufts with coagulative 
necrosis of the lining cells of glomerular tufts of some glomeruli (Fig. 2f). Meanwhile, a mild congestion of the renal blood vessels and intertubular capillaries with mild degenerative changes in the renal cortex as cloudy swelling (Fig. $2 \mathrm{~g}$ ) was detected in the lining epithelium of renal tubules with vacuolation of the endothelial cell lining of glomerular tuft in some animals obtained from group D. On other cases, hyper-cellularity of glomerular tuft and its adhesion with Bowman's capsule was also noticed (Fig. 2h).

Additionally, the lung from the exposed group showed congestion of pulmonary blood vessels with scattered hemorrhage in the pulmonary tissue with distension of some alveoli with erythrocytes (Figs. 3a\&b). Additionally, peri-bronchial leukocytic cellular infiltration mainly lymphocytes and macrophages (Fig. 3c) with an accumulation of eosinophilic edematous fluid in the lumen of some alveoli and alternated areas of emphysema of other alveoli were also observed among this group. Conversely, a mild congestion of inter-alveolar capillaries in association with few emphysematous alveoli (Fig. 3d) were the main pathological changes detected in rats obtained from group D.

Meanwhile, the main pathological changes detected in the heart of rats of group $\mathrm{C}$ were obvious congestion of myocardial blood vessels, degeneration in their wall, pericarditis that characterized by an increase in the thickness of pericardium with mononuclear leukocytic cellular infiltration (Fig. 3e), sever inter-muscular hemorrhages admixed with edematous fluid (Fig. 3f), degeneration of cardiac muscle characterized by discrete clear sarcoplasmic vacuolation in combination with hyaline degeneration of myocardium represented by homogenous deeply eosinophilic sarcoplasm with pyknosis or absence of their nuclei. In some cases, myelomalacia was noticed in which destruction of muscle fiber with the replacement of the muscle fiber with fibrous connective tissue in association with mononuclear leukocytic cellular infiltrations mainly lymphocytes (Fig. 3g). In group D, the congestion of myocardial blood vessels and the cardiac muscles were nearly similar to the control group (Fig. 3h). Rarely, intermuscular hemorrhages were seen only in one treated animal.

The spleen of rats in group $\mathrm{C}$ exhibited scattered areas of hemorrhages in the red pulp (Fig. 4a). Furthermore, multiple necrotic foci in the white pulp with apoptosis of some lymphoid cells were commonly observed (Fig. 4b). Extensive lymphoid depletion in some lymphoid follicles of the white pulp with hemorrhage (Fig. 4c), as well as hyperplasia and activation of erythropoietic center (Fig. 4d), was also demonstrated. Additionally, the interstitium was expanded by aggregates of mononuclear inflammatory cells mainly lymphocytes and macrophages. Meanwhile, in group D, a mild congestion of blood vessels of red pulp with the normal histological architecture of the splenic tissue with the proliferation of the lymphoid elements of white pulp with a mild lymphoid hyperplasia of the lymphoid follicles of white pulp was observed only in two examined cases (Fig. 4e\&f) with the absence of apoptosis of lymphocytes.

Interestingly, the most common microscopical findings in the brain tissue obtained from group $\mathrm{C}$, were congestion of meningeal, cerebral and cerebellar blood vessels and diffuse hemorrhage in the meninges as well as in the cerebellum with Perivascular lymphocytic cuffing (Fig. 5a). Congestion of choroid plexus and perivascular hemorrhage in the ventricles was seen. Multifocal hemorrhages were observed in different sites, particularly brain stem (Fig. 5b) with Peri-neuronal and personal edema with vacuolations was also noticed around the degenerated neurons (Fig. 5c). Focal areas of gliosis in the brain tissue were also seen (Fig. 5d) in association with focal areas of encephalomalacia characterized by abundant clear spaces infiltrated by erythrocytes and few lymphocytes was demonstrated (Fig. 5e). Area of rarefaction predominantly affecting the gray matter of cerebellum with necrosis and reduction in the number of Purkinje cells that take angular shape, deeply eosinophilic cytoplasm and pyknosis or absent nuclei (Fig. 5f) was also noticed. Furthermore, the brain showed a neuronal degeneration with swollen rounded cell bodies and indistinct or eccentric pyknotic nucleus as well as numerous microglia cells around the degenerated neurons manifested by microgliosis. Necrophagia was characterized by the engulfing of microglial cells to the necrotic neurons. No prominent microscopical changes were demonstrated in the brain tissue of group D, as the neurons displayed mild degenerative changes with a mild perivascular hemorrhage and a mild congestion of cerebellar blood vessels with elongation of its endothelial lining (Fig. 5g) in one case. The cerebral tissues revealed nearly normal Purkinje 
neurons with a mild edema of the Purkinje cell layer in most examined cases (Fig. 5h).

Table (1): Mean value of hematological parameters in response to radiofrequency radiations produced from mobile phone compared to their corresponding controls

\begin{tabular}{|c|c|c|c|c|}
\hline Blood parameters & Control (A) & Control (B) & $\operatorname{Group}(C)$ & Group(D) \\
\hline $\mathrm{RBC}(\mathrm{x10} / \mu \mathrm{l})$ & $11.26^{\mathrm{a}} \pm 0.29$ & $11.56^{\mathrm{a}} \pm 0.19$ & $8.18^{c} \pm 0.02$ & $9.37^{\mathrm{b}} \pm 0.01$ \\
\hline HB (g/dl) & $15.37^{\mathrm{a}} \pm 0.61$ & $15.87^{\mathrm{a}} \pm 0.99$ & $12.29^{\mathrm{c}} \pm 0.01$ & $14.42^{\mathrm{b}} \pm 0.1$ \\
\hline HCT(\%) & $53.19^{\mathrm{a}} \pm 0.01$ & $53.99^{\mathrm{a}} \pm 0.22$ & $41.42^{\mathrm{c}} \pm 0.01$ & $48.39^{\mathrm{b}} \pm 0.01$ \\
\hline MCV (fL/cell) & $59.21^{\mathrm{a}} \pm 0.01$ & $60.21^{\mathrm{a}} \pm 0.34$ & $50.29^{\mathrm{c}} \pm 0.01$ & $55.09^{\mathrm{b}} \pm 0.01$ \\
\hline MCH (pg/cell) & $15.24^{\mathrm{a}} \pm 0.29$ & $15.84^{\mathrm{a}} \pm 0.30$ & $14.06^{\mathrm{c}} \pm 0.15$ & $14.16^{\mathrm{b}} \pm 0.11$ \\
\hline $\operatorname{MCHC}(\mathrm{g} / \mathrm{dl})$ & $30.26^{\mathrm{ab}} \pm 1.14$ & $31.46^{\mathrm{ab}} \pm 1.16$ & $28.18^{\mathrm{c}} \pm 0.35$ & $29.27^{b} \pm 0.83$ \\
\hline $\mathrm{WBC}\left(\mathrm{x}^{3} 0^{3} / \mu \mathrm{l}\right)$ & $9.48^{\mathrm{c}} \pm 0.17$ & $9.27^{\mathrm{c}} \pm 1.44$ & $8.07^{\mathrm{b}} \pm 1.26$ & $15.17^{\mathrm{a}} \pm 0.15$ \\
\hline PLT $(\mathbf{x 1 0} / \mu \mathrm{l})$ & $865.34^{\mathrm{a}} \pm 4.21$ & $878.34^{\mathrm{a}} \pm 4.25$ & $649.24^{c} \pm 15.5$ & $787.18^{\mathrm{b}} \pm 26.5$ \\
\hline LYM \% & $23.53^{c} \pm 3.27$ & $24.23^{\mathrm{c}} \pm 3.44$ & $21.08^{b} \pm 2.61$ & $33.14^{\mathrm{a}} \pm 2.61$ \\
\hline
\end{tabular}

All data are presented as mean \pm SD for ten animals $(n=10)$. Values having different superscripts within the same row are significantly different at $\mathrm{P}<0.05$.

Table (2): Summary of the Incidence and severity of histopathological lesions in exposed mice to radiofrequency radiations produced from mobile phone and protected groups

\begin{tabular}{|c|c|c|c|c|c|c|c|c|}
\hline \multirow{3}{*}{ Organ/lesion } & \multicolumn{8}{|c|}{ Incidence $(\%)$ and severity of the histopathological lesions } \\
\hline & \multicolumn{4}{|c|}{ Group C } & \multicolumn{4}{|c|}{ Group D } \\
\hline & normal & mild & moderate & sever & normal & mild & moderate & sever \\
\hline \multicolumn{9}{|l|}{ Liver } \\
\hline $\begin{array}{l}\text { Congestion of hepatic blood } \\
\text { vessels }\end{array}$ & 0 & 0 & 30 & 70 & 60 & 40 & 0 & 0 \\
\hline $\begin{array}{ll}\text { Perivascular } & \text { Leukocytic } \\
\text { infiltration } & \end{array}$ & 0 & 10 & 40 & 50 & 80 & 20 & 0 & 0 \\
\hline Degenerative changes & 0 & 0 & 20 & 80 & 80 & 20 & 0 & 0 \\
\hline Necrosis of hepatic cells & 0 & 20 & 40 & 40 & 100 & 0 & 0 & 0 \\
\hline \multicolumn{9}{|l|}{ Kidney } \\
\hline Congestion of renal blood vessels & 0 & 20 & 40 & 40 & 60 & 40 & 0 & 0 \\
\hline Degeneration of blood vessels wal & 30 & 30 & 20 & 20 & 100 & 0 & 0 & 0 \\
\hline hemorrhage & 0 & 20 & 30 & 50 & 100 & 0 & 0 & 0 \\
\hline leukocytic cellular infiltration & 0 & 10 & 30 & 60 & 100 & 0 & 0 & 0 \\
\hline $\begin{array}{l}\text { Tubular epithelial degeneration } \\
\text { necrosis }\end{array}$ & 0 & 10 & 30 & 60 & 80 & 20 & 0 & 0 \\
\hline $\begin{array}{l}\text { Degeneration and necrosis of } \\
\text { glomerular tuft }\end{array}$ & 0 & 20 & 20 & 60 & 70 & 30 & 0 & 0 \\
\hline Shrinkage of the glomerular tuft & 0 & 10 & 30 & 60 & 100 & 0 & 0 & 0 \\
\hline \multicolumn{9}{|l|}{ Lung } \\
\hline $\begin{array}{l}\text { Congestion of pulmonary blood } \\
\text { vessels }\end{array}$ & 0 & 20 & 20 & 40 & 80 & 20 & 0 & 0 \\
\hline $\begin{array}{l}\text { Peri-bronchial } \\
\text { aggregation }\end{array}$ & 0 & 30 & 20 & 50 & 80 & 20 & 0 & 0 \\
\hline Emphysematous alveoli & 0 & 20 & 40 & 40 & 70 & 30 & 0 & 0 \\
\hline Diffuse hemorrhage & 0 & 10 & 30 & 60 & 100 & 0 & 0 & 0 \\
\hline \multicolumn{9}{|l|}{ Heart } \\
\hline Congestion & & 20 & 30 & 50 & 80 & 20 & 0 & 0 \\
\hline
\end{tabular}




\begin{tabular}{|c|c|c|c|c|c|c|c|c|}
\hline \multicolumn{9}{|l|}{ vessels } \\
\hline Pericarditis & 0 & 40 & 40 & 20 & 100 & 0 & 0 & 0 \\
\hline Intermuscular hemorrhage & 0 & 20 & 30 & 50 & 90 & 10 & 0 & 0 \\
\hline $\begin{array}{l}\text { Hyaline degeneration of car } \\
\text { muscle }\end{array}$ & & 40 & 30 & 30 & 100 & 0 & 0 & 0 \\
\hline myelomalacia & 50 & 40 & 10 & 0 & 100 & 0 & 0 & 0 \\
\hline \multicolumn{9}{|l|}{ spleen } \\
\hline $\begin{array}{l}\text { Congestion of splenic blood } \\
\text { vessels }\end{array}$ & 0 & 40 & 30 & 30 & 80 & 20 & 0 & 0 \\
\hline Hemorrhage & 0 & 30 & 20 & 50 & 100 & 0 & 0 & 0 \\
\hline Depletion of lymphoid follicles & 0 & 40 & 20 & 40 & 100 & 0 & 0 & 0 \\
\hline Apoptosis & 0 & 60 & 30 & 10 & 100 & 0 & 0 & 0 \\
\hline $\begin{array}{l}\text { Thickening and hyalinization of } \\
\text { blood vessels }\end{array}$ & 0 & 50 & 30 & 20 & 100 & 0 & 0 & 0 \\
\hline Macrophage cell infiltrations & 0 & 60 & 10 & 30 & 100 & 0 & 0 & 0 \\
\hline Lymphoid hyperplasia & 100 & 0 & 0 & 0 & 80 & 10 & 10 & 0 \\
\hline \multicolumn{9}{|l|}{ Brain } \\
\hline Congestion of blood vessels & 0 & 40 & 20 & 40 & 80 & 20 & 0 & 0 \\
\hline $\begin{array}{l}\text { Perivascular lymphocytic } \\
\text { cuffing }\end{array}$ & 0 & 60 & 20 & 20 & 100 & 0 & 0 & 0 \\
\hline Hemorrhage & 0 & 50 & 20 & 30 & 100 & 0 & 0 & 0 \\
\hline Neuronal degeneration & 0 & 40 & 30 & 30 & 80 & 20 & 0 & 0 \\
\hline Encephalomalacia & 0 & 30 & 20 & 50 & 100 & 0 & 0 & 0 \\
\hline Perineuronal edema & 0 & 50 & 30 & 20 & 90 & 10 & 0 & 0 \\
\hline cellular infiltrations & 0 & 60 & 30 & 10 & 100 & 0 & 0 & 0 \\
\hline
\end{tabular}
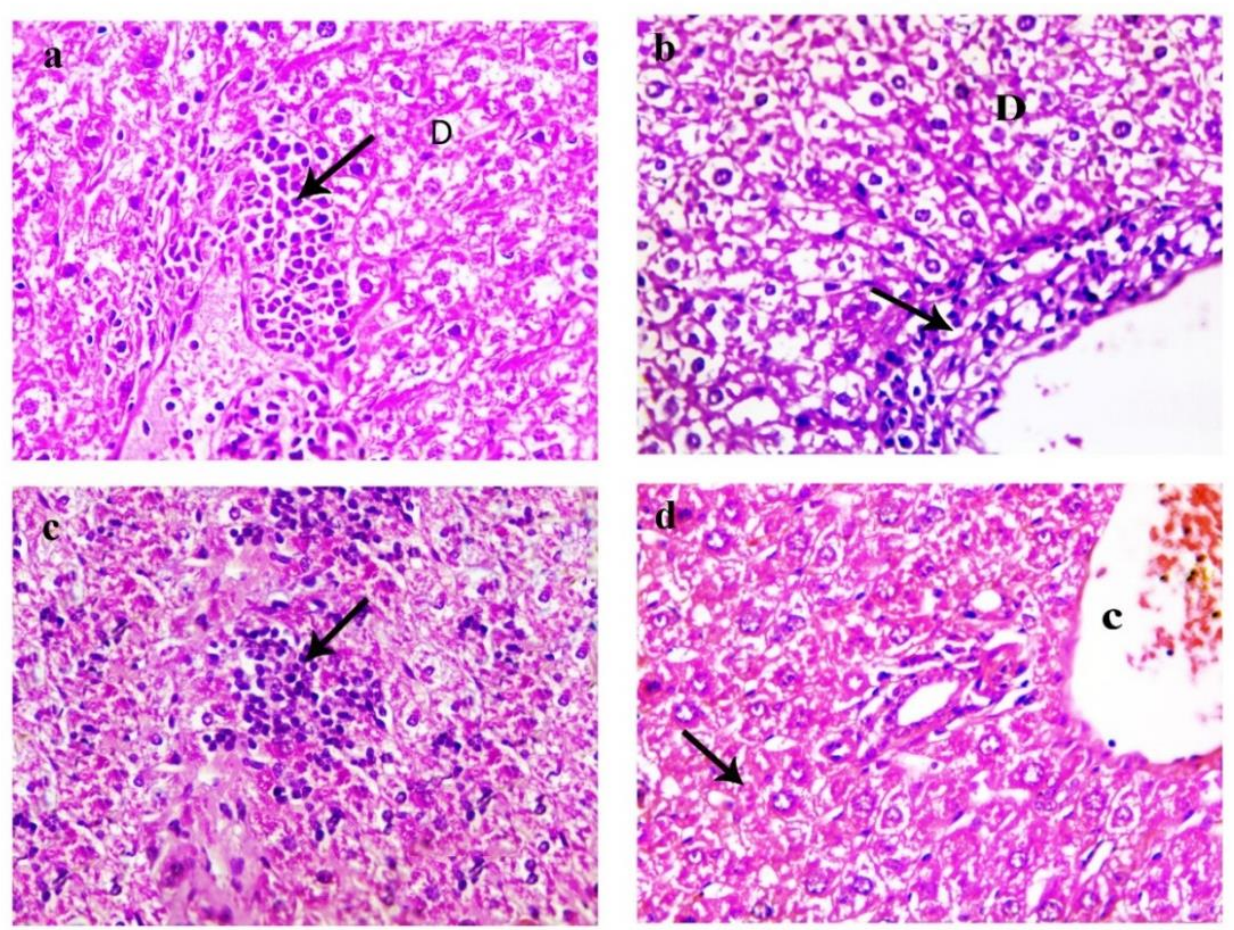

Fig. (1): H\&E stained sections of liver tissue taken from group C (a-c) and group D (d) showing (a) perivascular mononuclear leukocytic infiltration (arrow) with hydropic degeneration of hepatocytes (D, x400), (b) degenerative changes in the wall of blood vessels (arrow) with hydropic degeneration of hepatocytes characterized by swollen, pale, vacuolated cytoplasm with bi-nucleated hepatocytes (D, x400), (c) focal area of coagulative necrosis in the hepatic parenchyma (arrow, $x 400$ ), (d) mild) congestion of portal blood vessels $(C)$ with mild degenerative changes in the hepatocytes (arrow, $x 400$ ) 

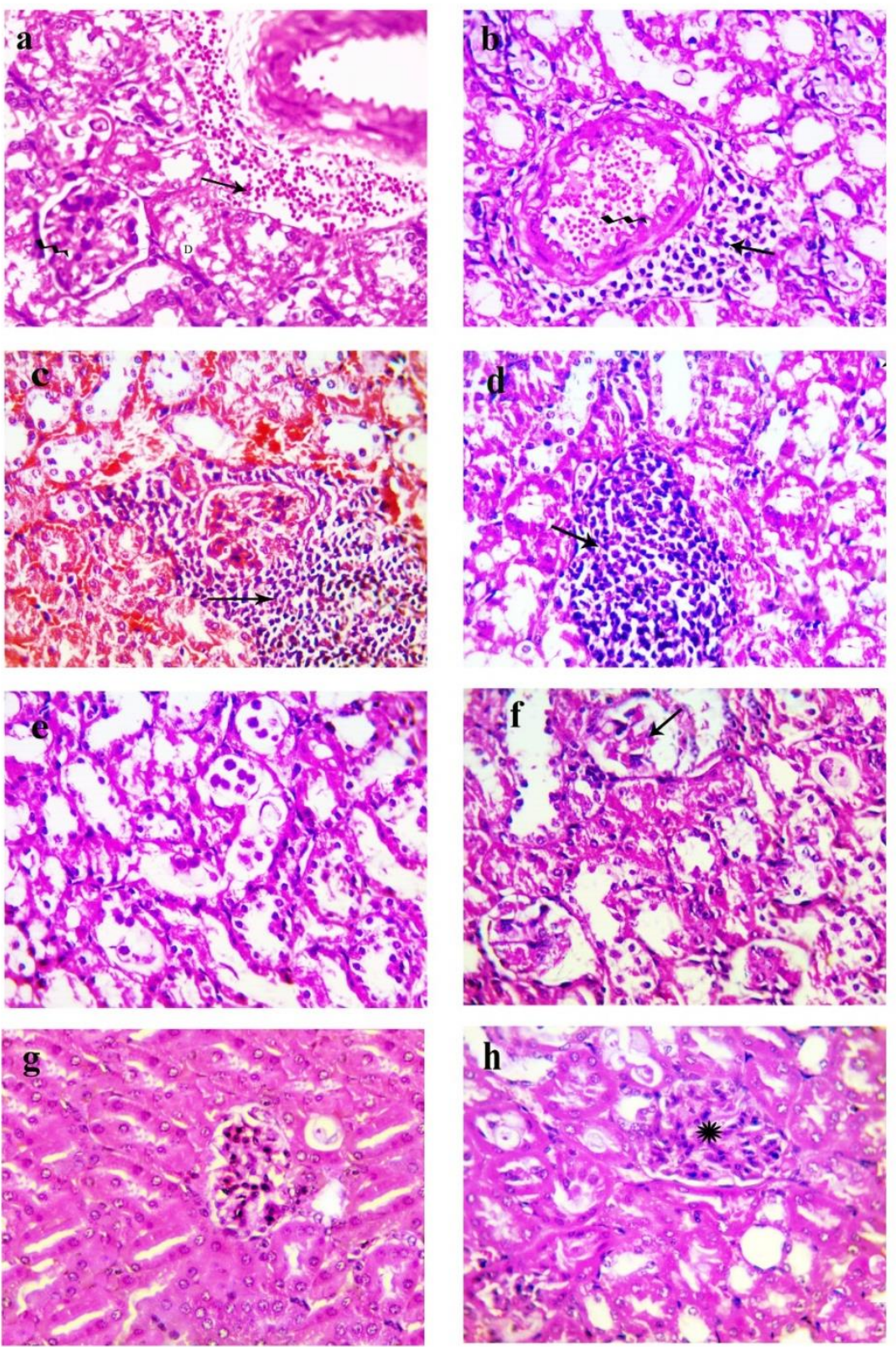

Fig. (2): kidney section stained with H\&E from group C (a-f) and group D (g-h) showing (a) perivascular hemorrhage (arrow) with vacuolation of the endothelial cell lining of glomeruli (zigzag arrow, x400), (b) marked hypertrophy of the endothelial cell lining of renal blood vessels (zigzag arrow) with perivascular mononuclear leukocytic infiltration (arrow, x400), (c) peri-glomerular leukocytic infiltration (arrow) with glomerular, Peri-tubular and intertubular hemorrhage (x200), (d) focal interstitial aggregations of mononuclear leukocytes (arrow) with vacuolation of the tubular epithelium (x200), (e) entire necrosis of the tubular epithelium with shrunken, pyknotic nuclei and loss of cellular details $(\mathbf{x 2 0 0})$, (f) coagulative necrosis of the endothelial cells lining of glomeruli with shrinkage of glomerular tufts (x200), (g) cloudy swelling of the lining epithelium of renal tubules (x200), (h) hypercellularity of glomerular tuft and its adhesion with Bowman's capsule (asterisk, x200) 

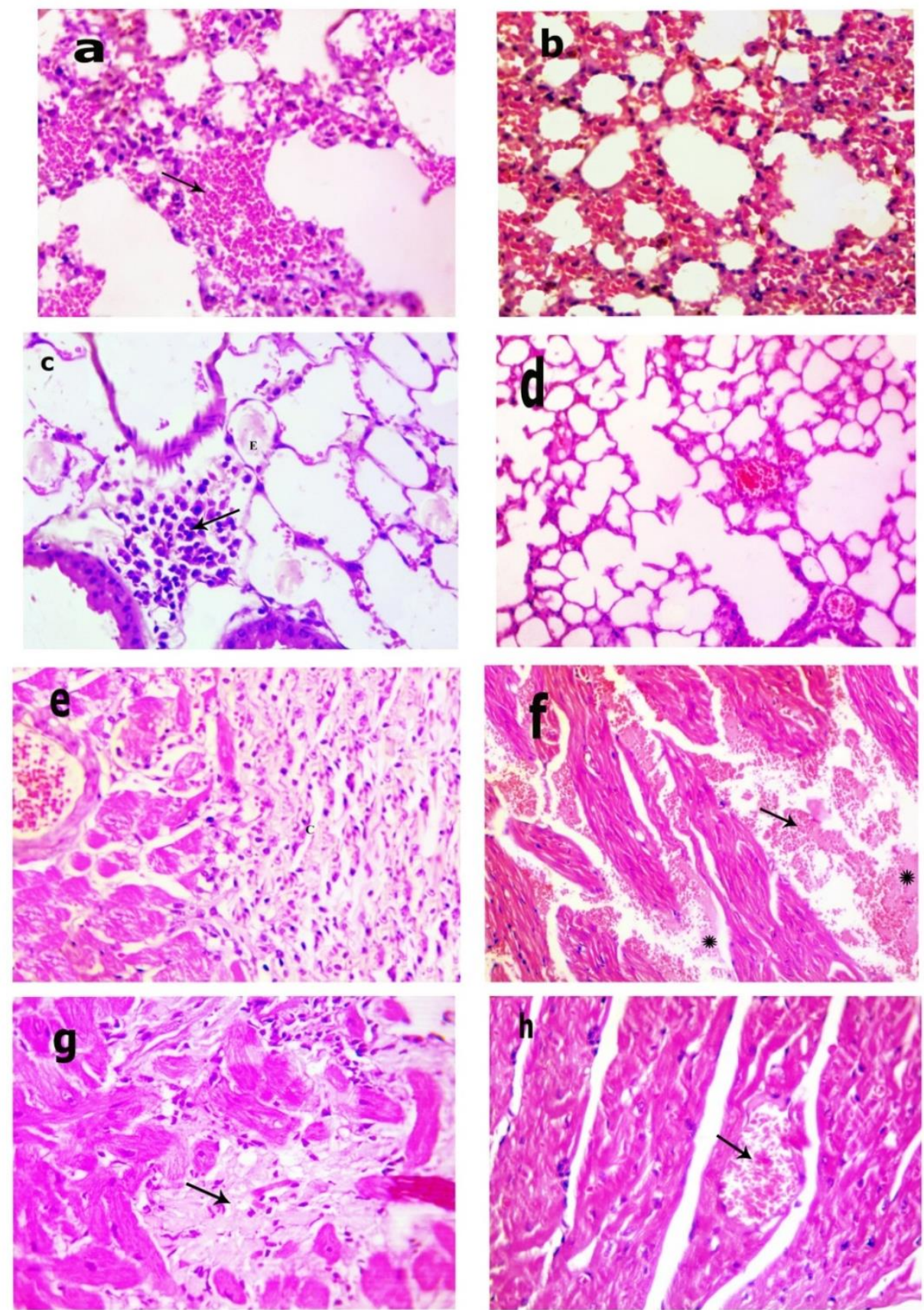

Fig. (3): lung section stained with H\&E from group C (a-c) and group D (d), (e-g) represent H\&E stained sections of heart tissue taken from group $C$ and (h) from group $D$ showing (a) scattered hemorrhage in the pulmonary tissue (arrow, x400), (b) distension of some alveoli with erythrocytes (x200), (c) peri-bronchial leukocytic cellular infiltration mainly lymphocytes and macrophages (arrow) with an accumulation of an eosinophilic proteinaceous substance in the lumen of some alveoli $(\mathrm{E}, \mathbf{x 4 0 0})$, (d) mild congestion of inter-alveolar capillaries in association with few emphysematous alveoli (x200), (e) pericarditis $(\mathrm{C}, \mathrm{x400)}$ ), (f) sever inter-muscular hemorrhages (arrow) admixed with edematous fluid (asterisk, x200), (g) myelomalacia (arrow, x400), Congestion of myocardial blood vessels (arrow) with the nearly normal histological structure of the cardiac muscles (x200) 

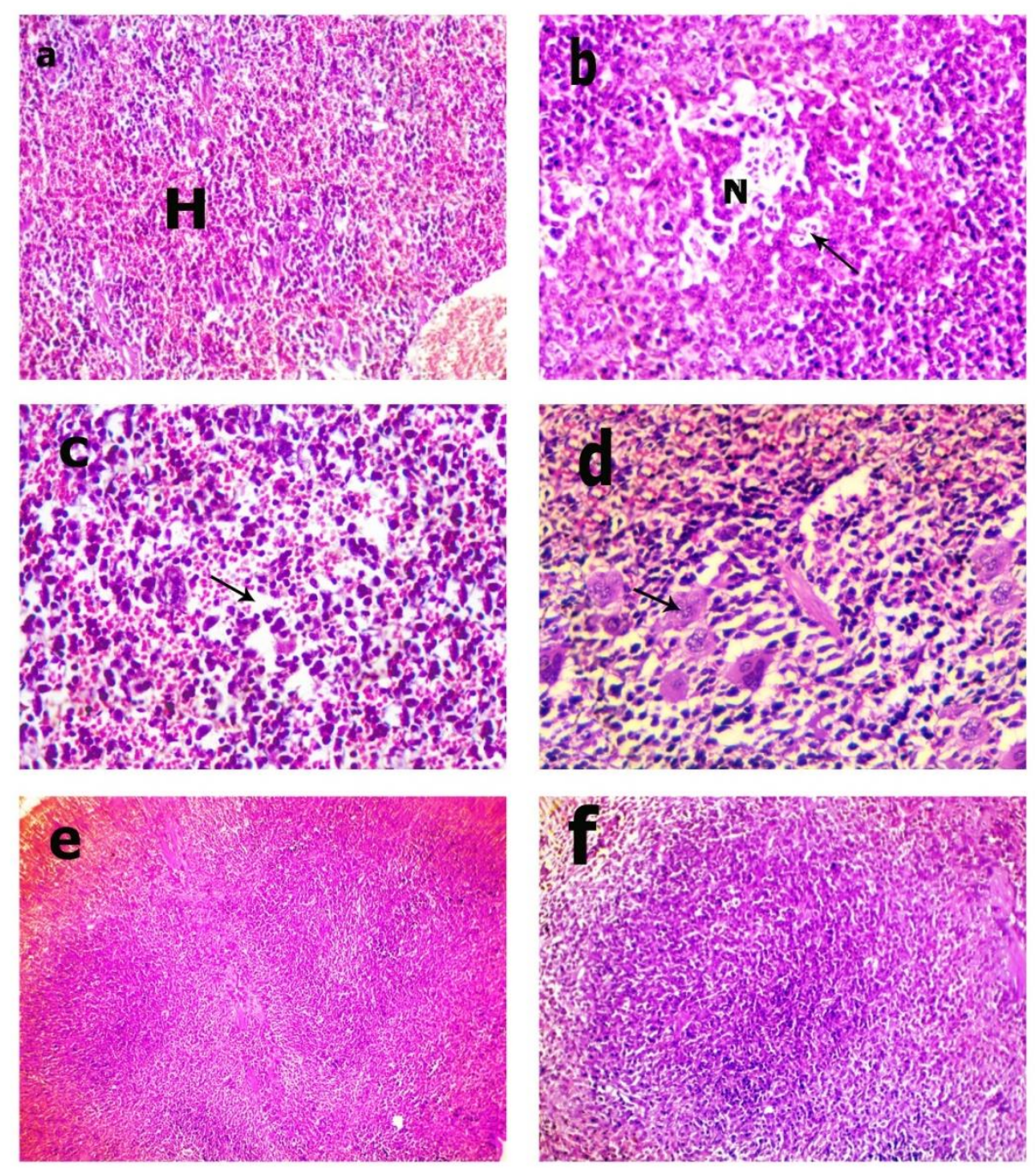

Fig. (4): spleen section stained with H\&E from group C (a-d) and group D (e-f) showing (a) scattered areas of hemorrhages in the red pulp $(H, x 100)$, (b) apoptosis (arrow) and necrosis $(N)$ of some lymphoid cells of the white pulp (x400), (c) extensive lymphoid depletion and hemorrhage in some lymphoid follicles of the white pulp (arrow, x200), (d)

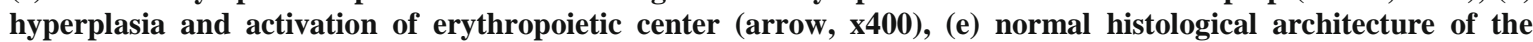
splenic tissue, (f) mild proliferation of the lymphoid elements of white pulp (x 100) 

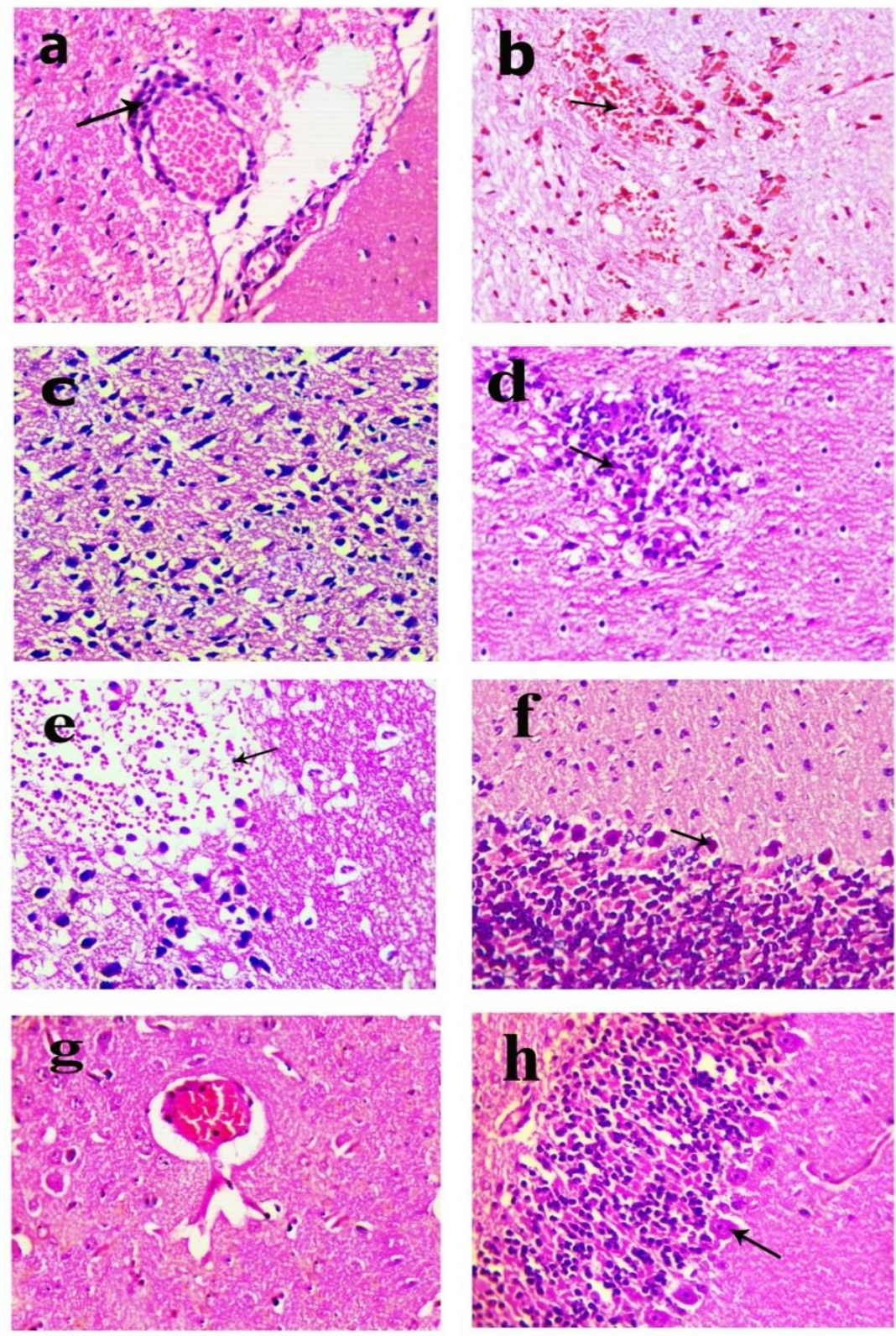

Fig. (5): brain section stained with H\&E from group C (a-f) and group D (g-h) showing (a) Perivascular lymphocytic cuffing(arrow, x400), (b) Multifocal areas of hemorrhages (arrow, x200), (c) Perineuronal and personal edema and vacuolations around the degenerated neurons (x200), (d) Focal areas of gliosis in the brain tissue (arrow, x200), (e) focal areas of encephalomalacia infiltrated with erythrocytes leukocytic cells mainly lymphocytes

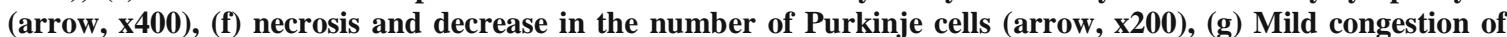
cerebellar blood vessels $(\mathbf{x} 400)$, (h) nearly normal Purkinje neurons with mild edema of the Purkinje cell layer (arrow, x200) 


\section{Discussion}

Radiofrequency released from cell phones have destructive effects on various tissues. In contrast, other studies suggested that no effects were reported post-exposure to cell phone radiation. Thus, numerous studies should be conducted in different fields to show more facts on the influences of mobile phones in order to provide international standards for protection. Consequently, the current work aimed to study the influence of radiation emitted from a mobile phone with some possible strategies to reduce the injurious effect of these radiations by using vitamin $\mathrm{E}$.

The blood parameters are the most significant means to determine the health status of experimental animals [13]. Thus, examining the influences of radiofrequency (RF) radiations from mobile phones on the hematological parameters acts as a beneficial marker of the possible effects of RF radiation on exposed animals. This is because of the blood reflects the pathophysiology of the whole body. In the current research, the results revealed that electromagnetic radiation from cell phones causes statistically significant changes in RBCs, Hb, HCT, MCV, MCHC, PLT and WBCs levels. These findings are in good agreement with previous publications $[6,7,8]$ and [14]. The electromagnetic radiations from cell phones have damaging effects on the blood cells and produced an imbalance in blood enzymes and increased cell apoptosis and functional disorders in many cell types [15]. Additionally, the detected alterations in the hematological parameters could also be attributed to the ability of radiations from mobile phones to induce stimulation of haemopoietic activity in the bone marrows and oxidative stress that resulting in anemia due to uncontrolled haemopioesis as confirmed by the obtained results in the current research. Furthermore, RF fields can change the leucocyte activities, including more rapid changes in the form of cell shrinking, expanding and rolling and lost its ability to move causing cell lysis and reduction in their number. However, the mobile phone disturbs the chemical composition of tissue since an electromagnetic energy exposure can change the electric current in the body. As an outcome of this exposure, the functions of organs are disturbed [3] on both sides of the plasma membrane, the electric fields exert a force on every free ion and cause them to pass it. These ion movements cause degradation in the ion channels on the membrane in association with biochemical modifications of the membrane, and thus all cellular functions are impaired $[16,17]$.

In the current research, various microscopical alterations were observed. These tissue damage could be attributed to the elevation level of reactive oxygen species (ROS) and the excessive free radical production and endogenous defense mechanisms could become inadequate. These free radicals destroying large cellular molecules such as lipids, proteins and nucleic acid [18]. Interestingly, extensive hemorrhage was noticed in the investigated organs that may be occurred due to the disruption of the blood capillaries walls. Additionally, the detected pathological alterations in the brain tissue that may be due to the Cell phones are kept near the head during use. Additionally, mobile phone radiation can affect neural functions in the exposed brain via its capacity to alter blood-brain barrier permeability and can create oxidative stress in brain tissue [19]. However, the metabolic activity of the brain and the demand for oxygen consumption are extremely high as well as neurons are largely depending on oxidative phosphorylation for energy and this makes them more susceptible to oxidative stress compared to other cells [20]. These findings could clarify the extensive pathological changes noticed in the neurons of animals exposed to RF radiation. In the present study, variable pathological changes were detected in the hepatic tissue of animals exposed to radiation of mobile phones. These results may be due to the direct influence of these radiations on hepatocytes that leads to leaking of cytosolic enzymes and energy metabolism disturbances and cell membrane disruptions in hepatocytes. Additionally, the cytotoxic effect of non-ionizing radiation on hepatocytes prompting apoptosis and necrosis [21]. Furthermore, vascular and interstitial damage of the renal tissue in combination with atrophic glomeruli and renal tubules with cytoplasmic vacuolation and pyknotic nuclei were noticed post-exposure to RF resulting in renal failure. These findings are matched with that demonstrated by other investigators [22].

Severe pathological changes were observed in the heart of rats exposed to mobile phones, these changes could result from the usage of mobile phones near the heart, therefore, radiofrequency radiation emitted from MP may be absorbed by the heart [23]. Although various pathological changes 
were demonstrated in the pulmonary tissue of animals exposed to mobile phone radiation in the present work, these pathological alterations in the lung have not yet been explained.

Vitamin E serves an important antioxidant in cellular membranes by blocking the peroxidation of polyunsaturated fatty acid (PUFA) constituents clinically. In the present study, a marked improvement in the pathological changes induced by mobile phone radiation was noticed in animals treated with vitamin $\mathrm{E}$. This may be attributed to the vital role of vitamin $\mathrm{E}$ in preventing oxidative stress and lipid peroxidation, scavenging free oxygen radicals and in stabilizing cell membranes, maintaining permeability resulting in a reduction in tissue damage induced by mobile phone radiation [24].

\section{Conclusion}

From the obtained results, it could be concluded that exposure to cell phones radiations results in a marked reduction in various blood parameters that might eventually lead to anemia in association with damage in different organs including liver, kidney, lung, heart, spleen and brain. Vitamin E has a marked ameliorative effect on these harmful reactions induced by radiofrequency radiation via its ability to reduce the harmful effects of mobile phone radiation on blood parameters and pathological changes in the lung, heart, spleen and brain tissues. Consequently, we have to get control over our mobile phones usage. Furthermore, there is a need for further experimental studies to be conducted in different fields to show more facts on the harmful effects of cell phones, especially on immune-reaction of the exposed animals as well as to establish more international standards for the protection against radiofrequency radiation.

\section{Reference}

1. Swerdlow AJ, Feychting M, Green AC, et al. (2011), Mobile phones, brain tumors, and the interphone study: where are we now? Environ Health Perspect; 119: 1534-1538.

2. Bhargava, S.; Motwani, M. B.; Patni, V. M., (2012), Effect of handheld mobile phone use on parotid gland salivary flow rate and volume. Oral surgery, oral medicine, oral pathology, and oral radiology, 114 (2), 200-206.

3. Megha K, Deshmukh PS, Banerjee BD, Tripathi AK, Abegaonkar MP (2012), Microwave radiation-induced oxidative stress, cognitive impairment and inflammation in the brain of Fischer rats. Indian J Exp Biol; 50: 889-896

4. Hao, Y.-H.; Zhao, L.; Peng, R.-Y., (2015), Effects of microwave radiation on brain energy metabolism and related mechanisms. Military medical research, 2 (1), 4.

Ahlbom, A.; Bridges, J.; de Seze, R.; Hillert, L.; Juutilainen, J.; Mattsson, M. O.; Neubauer, G.; Schuz, J.; Simko, M.; Bromen, K., (2008), Possible effects of electromagnetic fields (EMF) on human health--the opinion of the scientific committee on emerging and newly identified health risks (SCENIHR). Toxicology, 246: 248-50.

6. Singh, H.; Bagai, U., (2013), Effect of electromagnetic field on red blood cells of adult male swiss albino mice. Int $J$ Theor Appl Sci; 5: 175-82.

7. Kumari, P.; Manjula, S.; Gautham, K., (2016), In vitro study of the effect of radiation emitted by mobile phone on osmotic fragility and other blood parameters. Research Journal of Pharmaceutical, Biological, and Chemical Sciences, 7 (4), 1283-1292.

8. Mohammad A.; Esrafil M., Fatemeh p, Maryam M.; and Zahra A, (2016), Biochemical and Histological Effects of Mobile Phone Radiation on Enzymes and Tissues of Mice. research journal of Pharmaceutical, Biological and Chemical Sciences, 7: 0975-8585.

9. Zingg, J. M. (2007), Molecular and cellular activities of vitamin E analogs. Mini-Reviews. Medicinal Chemistry, 7: 545-560.

10. Escott-Stump S and Mahan LK, Krause's Food, Nutrition, and Diet Therapy. $10^{\text {th }}$ ed. WB Saunders, Philadelphia, PA (2000).

11. Mitchell Lewis, MD, FRC path, Barbara J and Imelda Bates Dacie and Pagana, KD and Pagana TJ, Mosbys Manual of Diagnostic and Laboratory Tests Louis mos by mos by Elsevier, (2010).

12. Suvarna, KS, Layton, C, Bancroft, JD, (2018), Bancroft's theory and practice of histological techniques E-Book

13. Soud, (2004), Human and the Environment (Education Study of the Environment). Dar AlHamed for Publication and Distribution," Journal of Environmental Studies; 1: 23-31.

14. Guo, L.; Lin, J.-J.; Xue, Y.-Z.; An, G.-Z.; Zhang, J.-P.; Zhang, K.-Y.; He, W.; Wang, H.; Li, W.; Ding, G.-R., (2019), Effects of 220 $\mathrm{MHz}$ pulsed modulated radiofrequency field on the sperm quality in rats. International journal

Arab J. Nucl. Sci. \&Applic. Vol. 53, No. 4 (2020) 
of environmental research and public health, $16(7), 1286$.

15. Atasoy, A.; Sevim, Y.; Kaya, I.; Yilmaz, M.; Durmus, A.; Sonmez, M.; Omay, S.; Ozdemir, F.; Ovali, E., (2009), The effects of electromagnetic fields on peripheral blood mononuclear cells in vitro. Bratisl Lek Listy, 110: 526-9.

16. Foster KR, Repacholi MH. (2004), Biological effects of radiofrequency fields: does modulation matter? Radiat Res; 162: 219-225.

17. Challis LJ. (2005), Mechanisms for interaction between RF fields and biological tissue. Bioelectromagnetics; 7: 98-106.

18. Balci M, Devrim E, Durak I.( 2007), Effects of mobile phones on oxidant/antioxidant balance in cornea and lens of rats. Curr Eye Res; 32: 21-5.

19. Meral, I., Mert, H., Mert, N., Deger, Y., Yoruk, I., Yetkin, A., \& Keskin, S (2007), Effects of 900-MHz electromagnetic field emitted from cellular phone on brain oxidative stress and some vitamin levels of guinea pigs. Brain Research; 1169: 120-124.

20. Nittby, H., Grafström, G., Eberhardt, J. L., Malmgren, L., Brun, A., Persson, B. R. R., \& Salford, L. G. (2008), Radiofrequency and Extremely Low-Frequency Electromagnetic Field Effects on the Blood-Brain Barrier.
Electromagnetic Biology and Medicine; 27: 103-126.

21. Lahijani MS, Tehrani DM, Sabouri E. (2009), Histopathological and ultrastructural studies on the effects of electromagnetic fields on the liver of preincubated white leghorn chicken embryo. Electromagn Biol Med; 28(4):391413.

22. Chauhan P, Verma HN, Sisodia R, Kesari KK. (2017), Microwave radiation $(2.45 \mathrm{GHz})$ induced oxidative stress: Wholebody exposure effect on histopathology of Wistar rats. Electromagnetic biology and medicine; 36: 2030.

23. Ozguner, F., A. Altinbas, M. Ozaydin et al. (2005), Mobile phone-induced myocardial oxidative stress: protection by a novel antioxidant agent caffeic acid phenethyle ester. Toxicol and Health, 21: 223-30.

24. Packer L, (1993), Vitamin E: biological activity and health benefits: Overview. p. 977982 in Packer L \& Fuchs J (eds.) Vitamin E in health and disease. New York, Marcel Dekker, Inc. 